\title{
Comments on the Article "The Effect of Positive Medial Cortical Support in Reduction of Pertrochanteric Fractures with Posteromedial Wall Defect Using a Dynamic Hip Screw": To the Editor
}

\author{
Su-Hyun Cho, MD \\ Department of Orthopaedic Surgery, Andong General Hospital, Andong, Korea
}

\section{To the Editor:}

The utility of additional fixations for sliding hip screws has been well demonstrated in the study entitled "Additional fixations for sliding hip screws in treating unstable pertrochanteric femoral fractures (AO type 31-A2): short-term clinical results." ${ }^{1)}$ I have read with great interest the recent study, "The effect of positive medial cortical support in reduction of pertrochanteric fractures with posteromedial wall defect using a dynamic hip screw," by Cho et al. ${ }^{2)}$ While I appreciate citation of my paper in this article, I have some concerns as follows.

First, reasoning from Table 3 of Ref. 2 and the total number of enrolled cases, I can conclude that all the cases were additionally fixed with either wire or trochanter stabilizing plate (TSP), or both: 26 cases were fixed with a wire alone; 72, with TSP alone; and 2, with both wire and TSP. Therefore, no use of wire for fragment fixation $(n=$ 72) refers to cases with TSP alone and no use of TSP ( $\mathrm{n}=$ 26) refers to cases with wire alone.

Second, the authors ${ }^{2)}$ divided 100 cases into three groups by intraoperatively assessing the status of medial cortical support after reduction. In group 2, 28 of 42 cases did not undergo additional posteromedial fixation, so they could be presumed to have undergone TSP because all the cases were additionally fixed with either wire or TSP, or both. The other 14 cases underwent additional posteromedial wire fixation. The authors ${ }^{2}$ stated that "Patients with additional posteromedial fixation showed significantly lower lag screw sliding $(p=0.02)$ 'than patients with TSP' might have been omitted." They consequently stated that cases with wire fixation showed significantly lower lag screw sliding than cases with TSP because there were no cases without any additional fixation (wire or TSP) and posteromedial fixation meant wiring. By the way, the authors described the effect of neck-shaft angle and lag screw sliding contingent upon the use of TSP or wire fixation of posteromedial cortex as statistically null in page 295 of Ref. 2. Therefore, they made inconsistent statements. Did they imply "no" statistical significance in the overall comparison of three groups while some statistical significance in the comparison of between two groups? This was not clearly described in the article and it does not make sense to me that there was no difference in the effect of posteromedial wiring and TSP, let alone the medial cortical variance, on the sliding distance and neck shaft angle. The effect of posteromedial wire fixation on sliding distance or neck-shaft angle should be studied between one group with it and the other group without it. It should not be studied by comparing with a group with TSP fixation because the effect of TSP should also be considered.

\section{CONFLICT OF INTEREST}

No potential conflict of interest relevant to this article was reported.

Received January 18, 2019; Accepted September 2, 2019

Correspondence to: Su-Hyun Cho, MD

Department of Orthopaedic Surgery, Andong General Hospital, Angsil-ro 11, Andong 36743, Korea

Tel: +82-54-840-1004, Fax: +82-54-821-1165

E-mail: suhyun1123@naver.com 
Letter to the Editor

Clinics in Orthopedic Surgery • Vol. 11, No. 4, $2019 \bullet$ www.ecios.org

\section{REFERENCES}

1. Cho SH, Lee SH, Cho HL, Ku JH, Choi JH, Lee AJ. Additional fixations for sliding hip screws in treating unstable pertrochanteric femoral fractures (AO Type 31-A2): shortterm clinical results. Clin Orthop Surg. 2011;3(2):107-13.
2. Cho MR, Lee JH, Kwon JB, Do JS, Chae SB, Choi WK. The effect of positive medial cortical support in reduction of pertrochanteric fractures with posteromedial wall defect using a dynamic hip screw. Clin Orthop Surg. 2018;10(3):2928. 


\section{Myung Rae Cho, Won-Kee Choi, Reply:}

Thank you for your interest in our paper. In the study, ${ }^{1)}$ we attempted to demonstrate the effect of positive medial cortical support on reduction of peritrochanteric fractures with posteromedial wall defects by using a dynamic hip screw. The cases were divided into three groups according to the cortical support. There were 28 positive cases, 42 neutral cases, and 30 negative cases.

You have pointed out that there are issues on our analysis of the effect of the use of trochanter stabilizing plate or wire. We admit that there could have been some errors in the analysis of the effect of an additional fixator. As we mentioned in the limitation, selection bias due to followup loss and retrospective design of the study could be the causes of the error.

However, there might be some confusion among the readers since the use of additional fixators could not be clearly distinguished according to the groups. So, we provide a table that depicts the use of additional fixators by each group (Table 1). We admit that it was difficult to evaluate the effectiveness of additional fixators, as you have mentioned, with those groups of patients. A larger pool of data will be needed to analyze the effect of additional fixation, and this was also the limitation of our paper. Thank you.

\section{CONFLICT OF INTEREST}

No potential conflict of interest relevant to this article was reported.
Correspondence to: Won-Kee Choi, MD

Department of Orthopaedic Surgery, Daegu Catholic University Medical Center, 33 Duryugongwon-ro 17-gil, Nam-gu, Daegu 42472, Korea Tel: +82-53-650-4277, Fax: +82-53-652-4272

E-mail: cwk1009@hanmail.net

\section{REFERENCE}

1. Cho MR, Lee JH, Kwon JB, Do JS, Chae SB, Choi WK. The effect of positive medial cortical support in reduction of pertrochanteric fractures with posteromedial wall defect us- ing a dynamic hip screw. Clin Orthop Surg. 2018;10(3):2928.

https://doi.org/10.4055/cios.2019.11.4.499

\section{Table 1. Use of Additional Fixators According to Groups}

\begin{tabular}{lccccc}
\multicolumn{1}{c}{ Variable } & DHS only & DHS + wire & DHS + TSP & DHS + wire + TSP & Total (N) \\
\hline Group 1 (positive) & 10 & 0 & 14 & 4 & 28 \\
Group 2 (neutral) & 10 & 2 & 18 & 12 & 42 \\
Group 3 (negative) & 2 & 2 & 18 & 8 & 30 \\
\hline
\end{tabular}

DHS: dynamic hip screw, TSP: trochanter stabilizing plate. 